\title{
How does Socio-Political Context Shape Daily Living: The Case of Jews and Arabs in Israel
}

\author{
Adital Ben-Ari, Yoav Lavee \\ University of Haifa, Haifa, Israel. \\ Email:adital@research.haifa.ac.il \\ Received October $12^{\text {th }}, 2010$; revised November $4^{\text {th }}, 2010$; accepted November $12^{\text {th }}, 2010$.
}

\begin{abstract}
The present paper addresses a timely topic by exploring the contribution of cultural, ethnic, and contextual attributes to close relationships within particular armed-political conflict. It is based on a series of studies to examine the daily lives of Jews and Arabs with different cultural orientations within the context of armed political conflict. In Study 1, we surveyed 697 Jewish and 300 Arab respondents to examine the extent to which daily occurrences are similarly experienced as stressful by different cultural and socio-political groups and how those occurrences relate to life and marital satisfaction. In Study 2, we employed a daily diary methodology with a sample of 300 couples to explore how daily fluctuations in psychological well-being and marital relationships relate to daily hassles. Security-related stress was perceived as the main source of stress for both Jews and Arabs, but on a daily basis it had little or no effect on well-being and marital relationships. The findings attest to the significance of the socio-political context within which people of different ethnic and cultural identity experience their daily lives. In so doing, this article advances new directions for theory and research.
\end{abstract}

Keywords: Cultural Orientation, Daily Hassles, Marital Relationships, Socio-Ethnic Affiliation, Well-Being

\section{Introduction}

What does it mean to suggest that individuals and couples are affected by their context? It can be said that the context in which individuals and couples operate involves the actual and potential influences that lie outside of the partners and their interactions (Karney, Story, \& Bradbury, 2005). Current research has been slow to consider the context of individuals and intimate relationships as a whole. Rather, most research on how individuals and couples are affected by their context has focused on a single or a few elements of the context at a time. In particular, despite the growing number of political conflicts and wars throughout the world, not enough scholarly attention has been paid to the patterns of distress experienced by individuals and couples living in such a context and to its socio-psychological consequences. The present study is aimed to fill this gap by examining the daily lives of individuals and couples within the context of armed political conflicts. In so doing, we intend to advance new directions for theory and research for understanding the impact of larger socio-political context and culture on close relationships and psychological well-being.

The global geo-political tension and armed conflict in the Middle East is most strongly reflected in the lives of Israeli Jews and Arabs. An important aspect of Israeli life is its continuous state of conflict with the neighboring Palestinian people and Arab countries. Wars, terrorist acts, and security threats are at the core of Israel's existential reality. This conflict has impacted on the daily experiences of both Jews and Arabs in Israel, disrupting the routine life of individuals and families alike. In the past decade, more than 1000 people have been killed and more than 7,000 injured in hostile activities, including stab-

This study was supported in part by a grant from the Israel Science Foundation (Grant number 808-01). bings, shootings, rocket shellings, and suicide and car bombings. Such violent events pose a threat to physical and mental health, to social and personal identity, and to the sense of membership in the community (Abdela, 2003). Yet, most Israelis, Jews and Arabs alike, continue to live their lives normally and go about their daily business, juggling between work and family responsibilities, participating in social and leisure activities, and investing in their personal and family well-being (Lavee \& Ben-Ari, 2003, 2008)

The impact of daily stresses on individuals and couples within the context of this armed political conflict was examined by employing a two-stage research design involving two methodologies. In the first stage, we conducted a survey to examine the sources of daily stress among married Jews and Arabs and the extent to which these sources of stress relate to life and marital satisfaction. In the second stage, we employed a daily diary approach to more closely examine how the daily experiences of stress are related to fluctuations in mood and couple relationships. Given that little research has looked at the unique cultural, ethnic, and contextual issues involved in stress and well-being; and given the lack of adequate theoretical frameworks to guide such research, the current paper may pave the way for the construction of a new body of knowledge.

\section{Contextual Background}

Two contextual components must be considered in studying the daily lives of Israelis: the diverse cultural makeup of the country and the security-political situation in the region. The Israeli population of about 7.1 million is composed of two main groups: Jews (75.7\%) and Arabs (19.8\%). The rest of the population consists primarily of non-Jewish immigrants from the former Soviet Union (Central Bureau of Statistics, 2008). Following massive waves of immigration from more than seventy 
countries, Israel is characterized by a mix of countries of origin, religions, traditions, and heritages. Traditional family patterns are found alongside modern lifestyles, Western culture coexists together with Middle-Eastern heritage, and religious values and practices range from secular to highly orthodox (Lavee \& Katz, 2003).

The small size of the country must also be taken into account to understand that for Israelis the armed conflict is not something that happens "out there", but right at home or nearby. This fact has ramifications at both the personal and collective levels. At the collective level, it makes the number of people who have been killed or injured more meaningful; at the personal level, it is likely that everyone in Israel intimately knows someone who has been killed or wounded in an act of war or terror. Consequently, the emotional highs and lows of the average Israeli tend to be affected by the state of security in the country. This effect is further intensified by the frequent recurrence of traumatic events, which have built up a cumulative sense of threat and personal vulnerability (Milgram, 1993).

\section{The Impact of Negative Daily Occurrences on Individuals and Couples}

Empirical evidence from a number of studies attests to the consequences of daily occurrences on people's psychological well-being and family relationships (Cassidy, 2000; DeLongis, Coyne, Dakof, Folkman, \& Lazarus, 1982; DeLongis, Folkman, \& Lazarus, 1988; Hahn \& Smith, 1999; van Eck, Nicolson, \& Berkhof, 1998). However, the significance of various daily occurrences may differ in different cultural and socio-political groups. Currently, the body of literature on daily stress has not given adequate consideration to cultural variations, and researchers of cultural variations have largely disregarded the effect of commonly experienced daily stresses on adaptational outcomes.

Cultural perspectives provide important insights into psychological processes (Oyserman \& Lee, 2008). Culture and socio-political affiliation may play a role in how individuals experience daily hassles, including the occurrence of events, their appraisal, the coping strategies used, and the adaptational outcomes (Slavin, Rainer, McCreary, \& Gowda, 1991). Certain kinds of events may be perceived as stressful in widely different cultures, but they may also be shaped by living and social conditions that are culture-specific or by variations in the sensitivity to certain events (Laungani, 1995, 2001; Mesquita \& Frijda, 1992; Scherer, 1997). Bringing concepts of culture into psychological theories and research will facilitate a better understanding of human diversity in context and is crucial to both social science and policy in multicultural societies (Cooper \& Denner, 1998; Hughes, Seidman, \& Williams, 1993; O’Donnell, 2006). Following this line of thought, the present study explores cultural variations in the everyday life experiences of Israel's two main socio-ethnic groups.

The most prominent framework within which cultural variations have been examined is based on Hofstede's (1980) and Triandis' (1995) distinction between individualist and collectivist cultures. In individualistic cultures, primarily associated with Western, industrialized societies, there is a strong commonly shared belief in the independence of self from others. Members of individualistic cultures tend to hold an independent view of the self that emphasizes separateness, internal attributes, and the uniqueness of individuals. As such, individualistic cultures tend to view behavior as a function of these personal attributes and emphasize values that promote individual goals. In contrast, members of collectivist cultures tend to hold an interdependent view of the self that emphasizes connectedness, social context, and relationships (Triandis, 1995). The major task for members of collectivist cultures is to fit in with and adjust to the relationships of their in-group, while constraining their own personal desires. Thus, collectivist cultures view situational factors, such as norms, roles, and obligations, as the major determinants of behavior and emphasize values that promote the welfare of their in-group (Hofstede, 1980; Kitayama, Markus, \& Lieberman, 1995; Smith \& Bond, 1993; Triandis, 1995). Today, most research on collectivist and individualist cultures has been carried out by means of cross-national studies. The cross-national literature indeed demonstrates an association between individualism-collectivism and psychological outcomes, in terms of both content and process (Oyserman \& Lee, 2008).

An apparent limitation of cross-national research is that different "cultures" are lumped together, as if they represent a uniform set of thoughts, beliefs, practices, and behaviors, and as if they have a shared history and religion (Slavin et al., 1991; Sundberg, 1981). While many scholars equate non-Western societies with "collectivism," not all collectivist cultures experience life events in a similar fashion (Laungani, 1995).

Another limitation of research on cultural variations in the experience and perception of stress stems from the emphasis on differences between societies, thus portraying different cultural communities as holding mutually exclusive, stable, and uniform views. The concept of culture is often confounded by related concepts, such as ethnicity, race, nation, and country (Hughes et al., 1993; Matsumoto, Takeuchi, Andayani, Kouznetsova, \& Krupp, 1998). There are two fundamental problems with operationalizing culture in terms of ethnic communities or countries. First, it creates an ecological fallacy (Babbie, 1989) by making assertions about one type of unit of analysis (i.e., culture) based on the examination of another (i.e., country or socio-political affiliation). Second, such a conception assumes the homogeneity of cultural orientations within communities. Indeed, it is more than likely that cultural diversity exists within countries just as it does between countries (Oyserman \& Lee, 2008). It may therefore be useful to study cultural orientation as a sociopsychological construct, referring to individual-level manifestations of individualism-collectivism (Triandis, 2001). In this regard, the term idiocentrism refers to individual-level individualism, whereas allocentrism refers to individual-level collectivism (Triandis, Leung, Villareal, \& Clack, 1985). In the same vein, Kitayama and colleagues (e.g., Kitayama, Duffy, \& Uchida, 2007; Markus \& Kitayama, 2003; Uchida, Kitayama, Mesquita, Reyes, \& Morling, 2008) have developed the independence-interdependence theory of cultural self suggesting that cultures vary in the relative emphasis on independence as opposed to interdependence in the definition of self.

In cross-national studies, Israel is most frequently characterized as a homogeneous society in terms of cultural orientation (e.g., Scherer, 1997). However, this view overlooks cultural differences within Israeli society. In fact, the Jewish majority in Israel is considered more modern, similar in many ways to "individualistic" Western societies, relative to the traditional, “collectivist” Israeli Arab population (Florian, Mikulincer, \& 
Weller, 1993; Haj-Yahia, 1997). Yet, even such a characterization of socio-ethnic groups in itself over-generalizes cultural orientation, as suggested by the substantial number of idiocentric Arabs and allocentric Jews (Lavee \& Katz, 2003). Given this cultural setting, the Israeli population provides a "natural laboratory" for examining cultural variations in the experience of daily hassles and for exploring how context shapes the daily lives of individuals and couples.

We examined cultural variations in daily experiences by two culturally-related dimensions: Socio-ethnic group affiliation (i.e., Jews vs. Arabs) and individual cultural orientation (i.e., idiocentric vs. allocentric). These two dimensions are likely to overlap to some extent, as the Jewish population tends to be characterized more often as idiocentric and the Arab minority as allocentric, however they do not coincide, because there are Arab Israeli citizens found with idiocentric cultural orientation and Jewish people with allocentric cultural orientation.

In Study 1, we examined the extent to which daily occurrences are similarly experienced and recognized as stressful by different cultural and socio-ethnic groups. What are the different sources of daily stresses and strains for both Jews and Arabs with either idiocentric or allocentric cultural orientations? How do psychological well-being and marital satisfaction relate to these sources of stress? In Study 2, we further explored how daily fluctuations in psychological well-being and marital relations are related to daily stressful occurrences among Jewish and Arab couples with different cultural orientations.

We expect that, given the context of political violence in the Middle East and the fact that terrorist attacks take place more frequently within Jewish communities, security-related stress will appear as the major source of stress for both Jews and Arabs, but will be appraised more negatively among Jewish respondents. In accordance with previous research (Lavee \& Ben-Ari, 2003; Lavee \& Ben-Ari, 2008), we expect that daily hassles will be negatively associated with psychological well-being and with marital relationships, with security-related stress having the strongest effect. We further expect that these associations will be moderated both by ethnic affiliation and cultural orientation, though we have no basis for predicting the direction of the effect.

\section{Study 1}

\section{Method}

Data collection for this study was carried out during the period of January-March, 2001. During this period, life in Israel was influenced by three major political events: the beginning of the Palestinian uprising (intifada) in October 2000; an intensification of tension between Israeli Arabs and Jews, which resulted in the death of 13 Arab youngsters; and the fall of the government, followed by national elections (which eventually led to a new government).

\section{Participants}

Two samples of 697 Jewish and 300 Arab respondents were drawn by means of a random telephone number dialing. The number of Arab respondents was somewhat inflated relative to their proportion of Israel's population (19\%) so as to enable appropriate statistical analyses. Forty-four percent of the total sample and of both Jewish and Arab sub-samples were men, and the rest (56\%) were women.

Preliminary analysis showed that after the elimination of respondents who were not clearly identified as idiocentric or allocentric, 396 of the Jewish respondents (59.8\%) were identified as idiocentric and 266 (40.2\%) were identified as allocentric. Among the Arab respondents, 214 (71.3\%) were identified as allocentric and $86(28.7 \%)$ were identified as idiocentric. Demographic characteristics of the sample are shown in Table 1. As the data in the Table 1 indicate, the four groups had a similar gender distribution and did not significantly differ in their mean age. However, the allocentrics were more likely to have been married for a longer period of time and to have more children. On average, respondents with an idiocentric orientation had a higher educational level and a higher income level than those with an allocentric orientation. In terms of religiosity level, the majority of the idiocentrics defined themselves as secular, whereas the allocentrics more often reported that they were traditional or orthodox.

\section{Procedure and Instruments}

Data were collected by a telephone survey, with the use of a computerized assisted telephone interviewing system. Trained interviewers conducted the interviews in Hebrew and Arabic with Jewish and Arab respondents, respectively.

Daily stresses and strains were measured by an adapted version of the Daily Hassles and Uplifts Scale (DeLongis et al., 1982). This instrument consists of a list of 18 items (e.g., "children”, “parents”, “spouse”, “work”, "health”, and "time for self") that can constitute sources of strain, stress, and hassle. Given the current geo-political situation in the Middle East, two other items were also included: "social-political events" and "security-related events." Respondents were asked to indicate whether or not each item had been a source of stress for them during the past week. Items were clustered into four domains of sources of stress: family (parents, children, spouse, in-laws, and other family relatives); self (appearance, time for self, and health); roles (work-related stress and household chores); and security-political (security and political situation).

Cultural orientation (idiocentrism-allocentrism) was measured by an adapted version of the Relational, Individual, and Collective Self-Aspect scale (Kashima \& Hardie, 2000). Respondents were asked to choose between two alternatives for various items measuring values and activities in relation to personal well-being (idiocentrism) versus group welfare (allocentrism). For example, "The most satisfying activity for me is: (a) doing something for myself, or (b) doing something for my group." On the basis of the responses to these items, respondents were categorized as having either an allocentric or an idiocentric orientation.

\section{Results}

To examine ethnic and cultural differences in the evaluation of daily hassles, a two-factor (ethnic affiliation and cultural orientation) multivariate analysis of variance was conducted across the four hassle domains (family, self, roles, and security-related stress). The results are presented in Table 2. The data show overall effects of ethnicity and cultural orientation, but no interaction effect. Closer inspection reveals that Jews are significantly more distressed by the security-political situation than are their Arab counterparts, $F=15.08, p<0.01$. Likewise, 
Jewish respondents are more disturbed than Arabs by family matters, $F=21.78, p<0.01$. As far as cultural orientation, people with an idiocentric orientation report more self-related hassles than do those with an allocentric orientation. The data further show an interaction effect in the evaluation of family hassles, $F$ $=3.89, p<0.05$, with allocentric Jews reporting more family hassles than their idiocentric counterparts. However, no difference was found between Arab idiocentrics and allocentrics in this regard. It is worthy of note that security-political concerns appear as the main source of stress for all groups - Jews and Arabs, idiocentric and allocentric alike.

\section{Association of Hassle Domains with Psychological \\ Well-Being and Marital Satisfaction}

Next, we examined the relations between the four hassle domains and the participants' personal well-being and marital satisfaction among the four groups (idiocentric and allocentric, Jews and Arabs). The findings are shown in Table 3. Overall, all hassle domains are negatively associated with personal well-being and marital satisfaction. Family-related hassles are most strongly associated with marital satisfaction, whereas self- related hassles are most strongly associated with personal well-being. In all groups, personal well-being is strongly associated with self-related concerns. In addition, personal wellbeing is also strongly related to role-related hassles among idiocentric Jews and to family-related hassles among idiocentric Arabs.

As shown in Table 3, the pattern of associations is not as clear in regard to marital satisfaction. With the exception of idiocentric Arabs, marital satisfaction is negatively associated with self-related hassles. It is also associated with role-related stress among idiocentric Jews and allocentric Arabs, and with family-related stress among idiocentric Arabs. Looking at it from another angle, it appears that for Jews, personal wellbeing and marital satisfaction are mostly correlated with selfand role-related hassles, whereas for Arabs they are mostly associated with family- and self-related hassles. Finally, although security-political concerns are the major source of stress for all groups, they are least likely to affect personal well-being and marital satisfaction.

Guided by the question of how the context of daily living in

Table 1.

Study 1 sample characteristics.

\begin{tabular}{|c|c|c|c|c|c|c|}
\hline \multirow{3}{*}{ Variable } & \multicolumn{2}{|c|}{ Jews } & \multicolumn{2}{|c|}{ Arabs } & \multirow{2}{*}{\multicolumn{2}{|c|}{ Group Differences }} \\
\hline & \multirow{2}{*}{$\begin{array}{c}\text { Idiocentrics } \\
\quad n=396 \\
\text { Mean }(S D)\end{array}$} & \multirow{2}{*}{$\begin{array}{c}\text { Allocentrics } \\
\quad n=266 \\
\text { Mean }(S D)\end{array}$} & \multirow{2}{*}{$\begin{array}{c}\text { Idiocentrics } \\
n=86 \\
\text { Mean }(S D)\end{array}$} & $\begin{array}{c}\text { Allocentrics } \\
n=214\end{array}$ & & \\
\hline & & & & & & \\
\hline Age & $\begin{array}{c}39.32 \\
(10.57)\end{array}$ & $\begin{array}{c}39.49 \\
(10.46)\end{array}$ & $\begin{array}{l}36.41 \\
(9.66)\end{array}$ & $\begin{array}{c}38.79 \\
(10.32)\end{array}$ & 2.13 & $d f$ \\
\hline Marital length & $\begin{array}{c}14.53 \\
(10.77)\end{array}$ & $\begin{array}{c}15.60 \\
(10.60)\end{array}$ & $\begin{array}{l}11.73 \\
(9.19)\end{array}$ & $\begin{array}{c}15.53 \\
(10.76)\end{array}$ & $3.34 *$ & 3, 958 \\
\hline Number of children & $\begin{array}{c}2.55 \\
(1.23)\end{array}$ & $\begin{array}{c}3.03 \\
(1.83)\end{array}$ & $\begin{array}{c}3.42 \\
(2.02)\end{array}$ & $\begin{array}{c}4.13 \\
(2.56)\end{array}$ & $30.34^{* *}$ & 3, 956 \\
\hline & $\%$ & $\%$ & $\%$ & $\%$ & $\chi^{2}$ & 3,831 \\
\hline Gender & & & & & 4.90 & \\
\hline Male & 47.1 & 38.7 & 46.5 & 45.5 & & \\
\hline Female & 52.9 & 61.3 & 53.5 & 54.5 & & \\
\hline Educational level & & & & & $186.80^{* *}$ & 3 \\
\hline Elementary & 3.1 & 6.0 & 18.6 & 28.8 & & \\
\hline Secondary & 26.2 & 37.2 & 33.7 & 46.2 & & \\
\hline Post-secondary & 17.6 & 24.8 & 11.6 & 12.5 & & \\
\hline University & 53.2 & 32.0 & 36.0 & 12.5 & & \\
\hline Income level & & & & & $189.98 * *$ & 9 \\
\hline Above average & 59.9 & 41.1 & 37.6 & 16.3 & & \\
\hline Average & 19.1 & 22.1 & 7.1 & 10.0 & & \\
\hline Below average & 21.0 & 36.8 & 55.3 & 73.7 & & \\
\hline Religion & & & & & $942.48 * *$ & 6 \\
\hline Jewish & 100.0 & 100.0 & -- & -- & & \\
\hline Moslem & -- & -- & 76.2 & 76.1 & & \\
\hline Christian & -- & -- & 15.5 & 12.0 & & \\
\hline Druze & -- & -- & 8.3 & 12.0 & & \\
\hline Level of religiosity & & & & & $126.62 * *$ & 12 \\
\hline Secular & 64.2 & 40.4 & 33.7 & 20.8 & & \\
\hline Traditional & 25.6 & 33.6 & 44.2 & 43.4 & & \\
\hline Orthodox & 10.2 & 26.0 & 22.1 & 35.8 & & \\
\hline
\end{tabular}

${ }^{*} p<0.05 . * * p<0.01$ 
Table 2.

Means, standard deviations (in parentheses), and multivariate analysis of variance of daily hassles by ethnic affiliation and cultural orientation.

\begin{tabular}{|c|c|c|c|c|c|c|c|c|c|}
\hline \multirow[b]{2}{*}{ Variable } & \multicolumn{3}{|c|}{ Jews } & \multicolumn{3}{|c|}{ Arabs } & \multicolumn{3}{|c|}{$F$} \\
\hline & $\begin{array}{c}\text { Idiocentrics } \\
n=396\end{array}$ & $\begin{array}{c}\text { Allocentrics } \\
n=266\end{array}$ & $\begin{array}{c}\text { Total } \\
n=662\end{array}$ & $\begin{array}{c}\text { Idiocentrics } \\
n=86\end{array}$ & $\begin{array}{c}\text { Allocentrics } \\
n=214\end{array}$ & $\begin{array}{c}\text { Total } \\
n=300\end{array}$ & Ethnic & Orient & $\mathrm{E} \times \mathrm{O}$ \\
\hline Self & $\begin{array}{c}0.29 \\
(0.29)\end{array}$ & $\begin{array}{c}0.25 \\
(0.27)\end{array}$ & $\begin{array}{c}0.27 \\
(0.28)\end{array}$ & $\begin{array}{c}0.33 \\
(0.30)\end{array}$ & $\begin{array}{c}0.26 \\
(0.27)\end{array}$ & $\begin{array}{c}0.28 \\
(0.28)\end{array}$ & 1.75 & $7.04 * *$ & 0.33 \\
\hline Roles & $\begin{array}{c}0.20 \\
(0.21)\end{array}$ & $\begin{array}{c}0.18 \\
(0.19)\end{array}$ & $\begin{array}{c}0.19 \\
(0.20)\end{array}$ & $\begin{array}{c}0.21 \\
(0.20)\end{array}$ & $\begin{array}{c}0.19 \\
(0.18)\end{array}$ & $\begin{array}{c}0.19 \\
(0.19)\end{array}$ & 0.68 & 1.90 & 0.09 \\
\hline Family & $\begin{array}{c}0.21 \\
(0.23)\end{array}$ & $\begin{array}{c}0.26 \\
(0.26)\end{array}$ & $\begin{array}{c}0.23 \\
(0.24)\end{array}$ & $\begin{array}{c}0.17 \\
(0.22)\end{array}$ & $\begin{array}{c}0.15 \\
(0.20)\end{array}$ & $\begin{array}{c}0.15 \\
(0.21)\end{array}$ & $21.78 * *$ & 0.94 & $3.59 *$ \\
\hline Security-political & $\begin{array}{c}0.81 \\
(0.39)\end{array}$ & $\begin{array}{c}0.82 \\
(0.39)\end{array}$ & $\begin{array}{c}0.82 \\
(0.39)\end{array}$ & $\begin{array}{c}0.62 \\
(0.49)\end{array}$ & $\begin{array}{c}0.67 \\
(0.47)\end{array}$ & $\begin{array}{c}0.66 \\
(0.48)\end{array}$ & $15.08^{* *}$ & 1.04 & 0.33 \\
\hline
\end{tabular}

Model $F(5,955)$ : Ethnicity $=14.19 * *$, Orientation $=2.92 *$, Ethnicity $\times$ Orientation $=1.15 .{ }^{*} p<0.05 .{ }^{* *} p<0.01$.

Table 3.

Correlations between daily stress domains and marital satisfaction and general well-being.

\begin{tabular}{|c|c|c|c|c|c|c|c|c|c|c|}
\hline \multirow[b]{3}{*}{ Variable } & \multicolumn{4}{|c|}{ Jews } & \multicolumn{4}{|c|}{ Arabs } & \multicolumn{2}{|c|}{ Total } \\
\hline & \multicolumn{2}{|c|}{$\begin{array}{l}\text { Idiocentrics } \\
\qquad(n=397)\end{array}$} & \multicolumn{2}{|c|}{$\begin{array}{l}\text { Allocentrics } \\
\qquad(n=266)\end{array}$} & \multicolumn{2}{|c|}{$\begin{array}{l}\text { Idiocentrics } \\
\qquad(n=86)\end{array}$} & \multicolumn{2}{|c|}{$\begin{array}{l}\text { Allocentrics } \\
\qquad(n=214)\end{array}$} & \multicolumn{2}{|c|}{$(n=963)$} \\
\hline & Mar-Sat & GWB & Mar-Sat & GWB & Mar-Sat & GWB & Mar-Sat & GWB & Mar-Sat & GWB \\
\hline Family & $-0.12 *$ & -0.08 & -0.09 & -0.10 & $-0.22^{*}$ & $-0.39 * *$ & -0.08 & $-0.18 *$ & $-0.27^{* *}$ & $-0.14 * *$ \\
\hline Self & $-0.16^{* *}$ & $-0.19 * *$ & $-0.30 * *$ & $-0.28^{* *}$ & -0.10 & $-0.32 * *$ & $-0.17^{*}$ & $-0.36 * *$ & $-0.19 * *$ & $-0.26 * *$ \\
\hline Roles & $-0.17^{* *}$ & $-0.19 * *$ & -0.04 & -0.12 & -0.13 & -0.13 & $-0.20 * *$ & -0.14 & $-0.13^{* *}$ & $-0.20 * *$ \\
\hline Security-political & -0.06 & -0.03 & -0.11 & $-0.13^{*}$ & -0.02 & -0.08 & -0.03 & -0.08 & $-0.09 * *$ & $-0.18^{* *}$ \\
\hline
\end{tabular}

Note: Mar-Sat $=$ marital satisfaction; GWB $=$ general well-being. ${ }^{*} p<0.05 .{ }^{* *} p<0.01$.

Israel affect the lives of Jews and Arabs, the findings indicate that security-political concerns are the major source of stress for all people living in Israel. At the same time, the fact that this source of stress appeared to have quite limited association with personal well-being and marital satisfaction further motivated us to examine more closely how the various sources of stress impact on people's psychological well-being and marital relationships on a day-to-day basis. More specifically, we examine the extent to which daily fluctuations in individuals' moods and sense of dyadic closeness are associated with family, self, roles, and security-related stress among Jewish versus Arab couples and among idiocentric versus allocentric individuals. We also examine the associations of each partner's experience of the four sources of stress with self and the other partner's mood and sense of closeness. In this regard, we treat individual's mood as a daily indicator of personal well-being and dyadic closeness as a daily indicator of the couple's marital relationship.

\section{Study 2}

\section{Method}

\section{Participants}

From the larger sample (Study 1), a random sub-sample of 300 respondents (200 Jewish and 100 Arab) were contacted and invited to participate in subsequent stages of the project, which included a session for completing self-report questionnaires, followed by a week-long structured daily diary. Participants were included in this stage only if both spouses were willing to take part in the research. Participants were paid \$ 50 in vouchers for their participation in the study. The present study is based on data from 272 couples (both husbands and wives) who provided complete data for all variables. This sample included 184 Jewish couples (67.6\%), of whom $71.7 \%$ were identified as idiocentric and $28.3 \%$ as allocentric, and 88 Arab couples (32.4\%), of whom $38.6 \%$ were identified as idiocentric and $61.4 \%$ as allocentric.

The sample characteristics are summarized in Table 4. As the data show, Jewish women were somewhat older than their Arab counterparts, and Jewish men and women had on average two more years of education than Arab men and women. Additionally, the number of children in Arab families was somewhat higher than in Jewish families. No differences were found between groups in the couples' length of marriage or in the men's age.

\section{Procedure}

Trained Jewish and Arab interviewers conducted interviews in Hebrew and Arabic. Interviewers visited the couples in their homes and administered questionnaires to each partner separately. The questionnaires included cultural orientation, personality and relationship measures, and background information. Following completion of the questionnaires, interviewers pro- 
vided instructions for filling out the daily diaries. Participants were instructed to start keeping the daily diaries the following day and to continue for seven consecutive days. They were further instructed to make their diary entries at the end of the day. Telephone calls were randomly made to participants during the week to check that the diaries were being completed as instructed and to answer any questions. Interviewers visited the participants' homes again at the end of the week to collect the diaries.

\section{Instruments}

Cultural orientation. Cultural orientation was measured by the adapted version of the Relational, Individual, and Collective Self-Aspect scale (Kashima \& Hardie, 2000), as described in Study 1. For respondents who participated in Study 1, this measure enabled an assessment of test-retest reliability. In addition, cultural orientation was measured for their spouses, who were not included in Study 1 . The test-retest correlation for spouses who participated in Study 1 was $r=0.53(p<0.01)$, and the between-spouses correlation of cultural orientation was $r=0.74(p<0.01)$. On the basis of data from both spouses, we classified couples into idiocentric and allocentric categories.

The daily diary. The daily diary contained four sections: daily hassles and uplifts, mood, dyadic closeness, and couple activities. Daily hassles were measured by an adapted version of the Daily Hassles and Uplifts Scale (DeLongis, Coyne, Dakof, Folkman, \& Lazarus, 1982). The instrument consisted of a list of 12 items (e.g., children, parents, spouse, work, health, security) that can constitute sources of stress. Respondents were asked to rate the extent to which each item had been a source of stress for them on a four-point Likert-type scale, ranging from 0 = not at all to $3=$ very much. Items were clustered into four domains: family, self, roles, and security-political by summing the scores of items in each domain for each day.

Mood. Mood was measured by 10 items from the Positive and Negative Affective Schedule (Watson, Clark, \& Tellegen,
1988). The original instrument consists of two 10-item scales (i.e., positive affect and negative affect) that were shown to be internally consistent and stable, with evidence of both convergent and discriminant validity. For the purposes of this research, the scale included 10 adjectives that identified five positive (e.g., relaxed, happy, excited) and five negative feelings (e.g., frustrated, depressed, irritable). Respondents were asked to report the extent to which they had experienced each feeling in the recent hours preceding reporting. Each item was rated on a four-point Likert-type scale, ranging from $1=$ not at all to $4=$ very much. Mood was computed as a mean score of the items after reversing the coding of negative items. The reliability $(\alpha)$ of the scale ranged between 0.76 and 0.79 for men and between 0.78 and 0.81 for women across the seven diary days.

Daily Closeness. The closeness scale was developed using information obtained from an earlier stage of the project. Qualitative in-depth interviews were conducted with 10 couples (20 interviewees), who were asked to describe their everyday experiences of closeness and distance. Analysis of the data showed that participants alluded to both physical and emotional closeness, and described closeness both as a wish for and as a sense of closeness (Author citation 3; Author citation 4). Consequently, the closeness scale in the current study was composed of four items in which respondents reported the extent to which they wished for physical and emotional closeness to their partners (e.g., "To what extent have you felt today a need for physical closeness to your spouse?”), and the extent to which physical and emotional closeness actually occurred on that day (e.g., "To what extent was there an emotional closeness between the two of you?"). Each item was measured on a five-point Likert-type scale, ranging from $1=$ not at all to $5=$ very much. A factor analysis indicated that all items loaded on a single factor. For each day, a closeness score was calculated as a mean of the four item scores. The mean internal consistency reliability $(\alpha)$ of the scale across the seven diary days was .90 for both men and women.

Table 4.

Study 2 sample characteristics.

\begin{tabular}{|c|c|c|c|c|c|}
\hline & \multicolumn{2}{|c|}{ Jews } & \multicolumn{2}{|c|}{ Arabs } & \multirow[b]{2}{*}{ Group Differences } \\
\hline & $\begin{array}{c}\text { Idiocentrics } \\
n=132\end{array}$ & $\begin{array}{c}\text { Allocentrics } \\
n=52\end{array}$ & $\begin{array}{c}\text { Idiocentrics } \\
n=34\end{array}$ & $\begin{array}{c}\text { Allocentrics } \\
n=54\end{array}$ & \\
\hline Variable & Mean $(S D)$ & Mean $(S D)$ & Mean $(S D)$ & Mean $(S D)$ & $F(3,268)$ \\
\hline \multicolumn{6}{|l|}{ Age } \\
\hline Husbands & $\begin{array}{c}41.30 \\
(10.85)\end{array}$ & $\begin{array}{c}43.94 \\
(10.16)\end{array}$ & $\begin{array}{l}41.44 \\
(9.56)\end{array}$ & $\begin{array}{c}41.58 \\
(10.16)\end{array}$ & 0.85 \\
\hline Wives & $\begin{array}{c}38.84 a b \\
(10.25)\end{array}$ & $\begin{array}{l}40.75 a \\
(9.77)\end{array}$ & $\begin{array}{c}35.56 \mathrm{~b} \\
(8.17)\end{array}$ & $\begin{array}{l}36.32 \mathrm{~b} \\
(9.38)\end{array}$ & $2.85^{*}$ \\
\hline \multicolumn{6}{|l|}{ Education (years) } \\
\hline Husbands & $\begin{array}{l}14.59 a \\
(2.93)\end{array}$ & $\begin{array}{l}14.37 \mathrm{a} \\
(2.88)\end{array}$ & $\begin{array}{c}12.88 \mathrm{~b} \\
(3.79)\end{array}$ & $\begin{array}{l}11.72 \mathrm{~b} \\
(4.00)\end{array}$ & $11.10^{* *}$ \\
\hline Wives & $\begin{array}{l}14.72 \mathrm{a} \\
(2.73)\end{array}$ & $\begin{array}{l}14.52 \mathrm{a} \\
(2.96)\end{array}$ & $\begin{array}{c}12.76 b \\
(3.30)\end{array}$ & $\begin{array}{l}12.51 \mathrm{~b} \\
(3.53)\end{array}$ & $9.17^{* *}$ \\
\hline Marital length & $\begin{array}{c}16.27 \\
(10.71)\end{array}$ & $\begin{array}{c}18.58 \\
(10.60)\end{array}$ & $\begin{array}{l}14.59 \\
(8.44)\end{array}$ & $\begin{array}{c}15.26 \\
(10.83)\end{array}$ & 1.30 \\
\hline Number of children & $\begin{array}{l}2.24 \mathrm{c} \\
(1.25)\end{array}$ & $\begin{array}{l}2.60 \mathrm{bc} \\
(1.11)\end{array}$ & $\begin{array}{l}3.06 \mathrm{ab} \\
(1.81)\end{array}$ & $\begin{array}{l}3.30 \mathrm{a} \\
(2.17)\end{array}$ & $7.18^{* *}$ \\
\hline
\end{tabular}

Note: Means within each row whose subscripts differ are different at $p<0.05 .{ }^{*} p<0.05$. ${ }^{* *} p<0.01$ 


\section{Results}

First, we conducted a two-way multivariate analysis of variance to examine the effects of ethnic affiliation and cultural orientation on the experience of daily hassles in the four domains among husbands and wives. The findings are presented in Table 5. The results indicate a main effect of ethnic affiliation, $F(8,261)=7.45, p<0.01$, but no effect of cultural orientation. A closer examination of the findings indicates that the Arab men and women reported higher levels of daily stress than their Jewish counterparts in family, self, and role-related stress. In addition, the Arab men reported a higher level of security-related stress as compared to the Jewish men. Differences between idiocentrics and allocentrics were found only in the experience of security-related stress among the men, with idiocentric men reporting a higher level of security-related stress than allocentric men. Finally, an interaction effect was found in the experience of role-related stress among women, with idiocentric Arab women reporting a higher level of stress than their allocentric counterparts, while allocentric Jewish women reported a higher level of stress than idiocentric Jewish women.

Next, we examined the pattern of correlations between hassle domains and individual's mood and dyadic closeness among husbands and wives in the four groups. The findings are depicted in Table 6. Overall, there are negative correlations between daily hassles and men's mood across all hassle domains. For women, daily mood is negatively associated with all but security-related stress. A closer examination reveals that this pattern of correlations exists particularly among Jewish participants, both men and women. In contrast, none of the daily hassle domains are correlated with Arab men's mood, and only family-related stress is associated with mood among both idiocentric and allocentric Arab women.

Dyadic closeness appears to have a much lower impact on daily stress than individual's mood. Only among women, sense of closeness was significantly related to family and self-related stress. Closeness is related primarily to self-related stress among Jewish women, whereas it is more strongly associated with family-related hassles among Arab women, though not to a statistically significant level.

In the final stage of analysis, we examined the extent to which individual's mood and sense of dyadic closeness are associated with one's own and one's partner's experiences of daily stress. The findings are provided in Table 7. For each outcome variable (i.e., individual's mood, dyadic closeness), two models are presented. Model 1 (a base model) illustrates the associations between the actor's outcome variables and the actor's and partner's stress domains (level 1). Model 2 demonstrates how these associations are moderated by ethnic affiliation and cultural orientation (level 2).

\section{Daily Stress Effect on Mood}

The findings in Model 1 indicate that daily mood is negatively associated with the actor's stress in all four domains, whereas it is only associated with the partner's experience of security-related stress. Model 2 shows no group differences in the level of the individual's mood (i.e., insignificant main effects of ethnic affiliation and cultural orientation groups). It further shows that the associations between the actor's mood and the actor's and partner's stress domains are partly moderated by ethnic affiliation, but not by cultural orientation. More specifically, it appears that the effects of both the actor's and the partner's security-related stress on one's mood are different for Jews and Arabs.

In order to further explore these differences, we examined the pattern of associations between the actor's and the partner's security-related stress and mood among Jews and Arabs. The findings show statistically significant negative correlations among the Jews ( $r=-0.16$ and $r=-0.12, p<0.001$ for actor and partner, respectively), whereas the correlations are statistically insignificant among the Arabs ( $r=0.02$ and $r=0.01$ ). Group differences were also found with respect to the effect of the actor's role-related stress on mood. A closer examination of this effect shows a stronger negative correlation among the Jews as compared to the Arabs $(r=-0.27$ and $r=-0.11$, respectively), reaching a statistically significant difference $(z=$ $-4.80, p<0.001)$. Finally, among the Jews but not among the Arabs, the actor's mood is negatively associated with the partner's self-related stress.

\section{Daily Stress Effect on Closeness}

The findings in Model 1 indicate that dyadic closeness is negatively associated with both the actor's and the partner's stress in all four domains, with the exception of the actor's experience of security-related stress. Model 2 shows no group differences in the level of dyadic closeness (i.e., insignificant main effects of ethnic affiliation and cultural orientation groups). It further shows that neither ethnic affiliation nor cultural orientation have a moderating effect on these associations. In other words, similar patterns of association exist for both Jews and Arabs with idiocentric and allocentric orientations.

\section{Discussion}

The present paper addresses a timely topic by exploring the contribution of cultural, ethnic, and contextual attributes to close relationships within particular armed-political conflict. It is based on a series of studies conducted within the socio-political Israeli context, in an attempt to answer three questions: What are the different sources of daily stresses and strains for both Jews and Arabs with either idiocentric or allocentric cultural orientations? How do psychological well-being and marital satisfaction relate to these sources of stress? How are daily fluctuations in psychological well-being and marital relations related to daily stressful occurrences among Jewish and Arab couples with different cultural orientations? By integrating the answers to these three questions, we will highlight the way in which culture, ethnic affiliation, and the socio-political context shapes the daily lives of individuals and couples. In so doing, the current article may identify new directions for theory and research.

\section{Major Sources of Daily Stresses and Strains for People in an Armed Political Conflict}

As expected, security-related stress was found to be the major source of stress for both Jews and Arabs with either idiocentric or allocentric cultural orientations (Study 1). However, when considered on a daily basis (Study 2), this did not appear to be the case. This gap may be attributed to the differential ways in which Israelis appraise and deal with security concerns. In terms of a global evaluation, when asked about their every- 
day living, most people refer to the security situation as a primary concern that shapes their lives. However, on a daily basis, unless an act of terrorism or political violence has recently occurred, people tend to go about their ordinary routines without giving special consideration to security concerns.

The fact that security-related stress is the source of stress most strongly experienced by Israelis, and that it is experienced more strongly among Jews than Arabs, may be explained by the existential threat posed by the armed conflict and political violence in this country. For people living under such circumstances, other sources of stress may appear to be of secondary significance.

Differences were found between various ethnic and cultural groups in the extent to which they experienced and appraised other sources of daily stress. For example, people with an idiocentric cultural orientation were more concerned with selfrelated stress than their allocentric counterparts, and differences in the appraisal of family-related stress were found between allocentric and idiocentric Jews, but not Arabs. The finding that selfrelated stress (i.e., appearance, time for self) is more strongly experienced by people with an idiocentric orientation is not surprising because it is one of the major characteristics of individualistic cultures. In the same vein, the fact that family-related stress (i.e., relations among family members) did not differentiate between allocentric and idiocentric Arabs reflects the significance of family relationships in their collectivist culture.

Table 5.

Means, standard deviations (in parentheses), and multivariate analysis of variance of daily hassles by ethnic affiliation and cultural orientation.

\begin{tabular}{|c|c|c|c|c|c|c|c|c|c|}
\hline \multirow[b]{2}{*}{ Variable } & \multicolumn{3}{|c|}{ Jews } & \multicolumn{3}{|c|}{ Arabs } & \multicolumn{3}{|c|}{$F(1,268)$} \\
\hline & $\begin{array}{l}\text { Idiocentrics } \\
(\mathrm{n}=132)\end{array}$ & $\begin{array}{l}\text { Allocentrics } \\
\quad(\mathrm{n}=52)\end{array}$ & Total & $\begin{array}{l}\text { Idiocentrics } \\
(\mathrm{n}=34)\end{array}$ & $\begin{array}{l}\text { Allocentrics } \\
(\mathrm{n}=54)\end{array}$ & Total & E & $\mathrm{C}$ & $\mathrm{E} \times \mathrm{C}$ \\
\hline \multicolumn{10}{|l|}{ Husbands } \\
\hline Family & $2.67(2.62)$ & $2.27(2.27)$ & $2.56(2.53)$ & $3.18(2.60)$ & 3.15 (2.69) & $3.16(2.64)$ & $3.87^{*}$ & 0.38 & 0.29 \\
\hline Self & $3.30(3.27)$ & $3.37(2.81)$ & $3.32(3.14)$ & $4.32(3.43)$ & 5.09 (3.48) & $4.80(3.46)$ & $9.60 * *$ & 0.89 & 0.62 \\
\hline Roles & $4.32(2.74)$ & 3.81 (3.33) & $4.18(2.92)$ & $5.79(2.58)$ & $5.00(3.25)$ & $5.31(3.02)$ & $10.89 * *$ & 2.65 & 0.12 \\
\hline Security & $3.23(2.34)$ & $2.81(2.50)$ & 3.11 (2.39) & $4.91(2.40)$ & 3.91 (2.16) & $4.30(2.30)$ & $18.90^{* *}$ & $4.94 *$ & 0.83 \\
\hline \multicolumn{10}{|l|}{ Wives } \\
\hline Family & $3.14(2.60)$ & $3.71(2.90)$ & $3.30(2.70)$ & $4.30(2.83)$ & $4.02(2.60)$ & $4.12(2.70)$ & $3.94 *$ & 0.16 & 1.32 \\
\hline Self & $4.50(2.91)$ & $4.20(2.92)$ & $4.41(2.91)$ & $5.65(3.50)$ & $6.50(3.54)$ & $6.16(3.52)$ & $16.26^{* *}$ & 0.38 & 1.80 \\
\hline Roles & $5.01(2.66)$ & $5.35(2.90)$ & $5.10(2.73)$ & $7.53(3.01)$ & $5.83(2.28)$ & $6.50(2.70)$ & $16.82 * *$ & 3.42 & $7.69 * *$ \\
\hline Security & $3.64(2.50)$ & $3.90(2.33)$ & $3.71(2.44)$ & 3.94 (2.53) & 3.15 (2.10) & $3.45(2.30)$ & 0.44 & 0.70 & 2.54 \\
\hline
\end{tabular}

Note: $\mathrm{E}=$ Ethnicity, $\mathrm{C}=$ Cultural orientation. Model $F(8,261)$ : Ethnicity $=7.45^{* *}$, Cultural orientation $=1.51$, Ethnicity $\times$ Culture $=2.00^{*} .{ }^{*} p<0.05 .{ }^{* *} p<0.01$.

Table 6.

Correlations between mean daily stress domains and mean mood and closeness scores across 7 days.

\begin{tabular}{|c|c|c|c|c|c|c|c|c|c|c|}
\hline \multirow[b]{3}{*}{ Variable } & \multicolumn{4}{|c|}{ Jews } & \multicolumn{4}{|c|}{ Arabs } & \multicolumn{2}{|c|}{ Total } \\
\hline & \multicolumn{2}{|c|}{$\begin{array}{l}\text { Idiocentrics } \\
\quad(n=132)\end{array}$} & \multicolumn{2}{|c|}{$\begin{array}{l}\text { Allocentrics } \\
\qquad(n=52)\end{array}$} & \multicolumn{2}{|c|}{$\begin{array}{l}\text { Idiocentrics } \\
\quad(n=34)\end{array}$} & \multicolumn{2}{|c|}{$\begin{array}{l}\text { Allocentrics } \\
\qquad(n=54)\end{array}$} & \multirow[b]{2}{*}{ Closeness } & \multirow[b]{2}{*}{ Mood } \\
\hline & Closeness & Mood & Closeness & Mood & Closeness & Mood & Closeness & Mood & & \\
\hline \multicolumn{11}{|l|}{ Husbands } \\
\hline Family & -0.04 & $-0.34 * *$ & -0.06 & $-0.50^{* *}$ & 0.02 & -0.12 & -0.09 & -0.12 & -0.05 & $-0.30 * *$ \\
\hline Self & $-0.18^{*}$ & $-0.31^{* *}$ & -0.11 & $-0.33^{*}$ & -0.04 & -0.12 & 0.17 & -0.10 & -0.10 & $-0.25 * *$ \\
\hline Roles & -0.14 & $-0.49 * *$ & -0.11 & $-0.45^{* *}$ & 0.29 & -0.13 & 0.27 & -0.17 & -0.01 & $-0.38 * *$ \\
\hline Security & 0.07 & -0.16 & -0.19 & $-0.33^{*}$ & 0.17 & 0.11 & 0.13 & 0.07 & 0.04 & $-0.13^{*}$ \\
\hline \multicolumn{11}{|l|}{ Wives } \\
\hline Family & -0.13 & $-0.25^{* *}$ & -0.17 & $-0.44^{* *}$ & -0.21 & $-0.36^{*}$ & -0.10 & -0.26 & $-0.15^{*}$ & $-0.30 * *$ \\
\hline Self & $-0.21^{*}$ & $-0.26^{* *}$ & $-0.32 *$ & $-0.36^{* *}$ & -0.09 & -0.12 & 0.06 & -0.11 & $-0.16^{* *}$ & $-0.22 * *$ \\
\hline Roles & -0.09 & $-0.28^{* *}$ & -0.16 & -0.27 & -0.05 & -0.02 & -0.02 & -0.09 & -0.08 & $-0.19 * *$ \\
\hline Security & 0.03 & -0.16 & -0.05 & -0.17 & 0.16 & 0.29 & -0.08 & 0.07 & 0.03 & -0.06 \\
\hline
\end{tabular}

${ }^{*} p<0.05 .{ }^{* *} p<0.01$ 
Table 7.

Summary table of multilevel analyses for the effects of actor $(A)$ and partner $(P)$ stress domains on mood and dyadic closeness.

\begin{tabular}{|c|c|c|c|c|}
\hline \multirow[b]{2}{*}{ Variable } & \multicolumn{2}{|c|}{ Mood } & \multicolumn{2}{|c|}{ Closeness } \\
\hline & Base model & Culture + Group & Base model & Culture + Group \\
\hline Intercept & $2.87(0.02)^{* *}$ & $2.85(0.02)^{* *}$ & $3.10(0.04)^{* *}$ & $3.10(0.04)^{* *}$ \\
\hline Group & & $0.05(0.04)$ & & $0.09(0.10)$ \\
\hline Culture & & $-0.04(0.03)$ & & $-0.15(0.08)$ \\
\hline A-family & $-0.11(0.01)^{* *}$ & $-0.11(0.01)^{* *}$ & $-0.08(0.03)^{* *}$ & $-0.08(0.03)^{* *}$ \\
\hline By Group & & $0.01(0.03)$ & & $-0.07(0.06)$ \\
\hline By Culture & & $-0.01(0.03)$ & & $-0.00(0.06)$ \\
\hline A-self & $-0.09(0.01)^{* *}$ & $-0.09(0.01)^{* *}$ & $-0.07(0.02)^{* *}$ & $-0.07(0.02)^{* *}$ \\
\hline By Group & & $0.02(0.02)$ & & $-0.00(0.05)$ \\
\hline By Culture & & $-0.04(0.03)$ & & $-0.05(0.05)$ \\
\hline A-roles & $-0.10(0.01)^{* *}$ & $-0.10(0.01)^{* *}$ & $-0.10(0.02)^{* *}$ & $-0.10(0.02)^{* *}$ \\
\hline By Group & & $0.07(0.02)^{* *}$ & & $0.05(0.05)$ \\
\hline By Culture & & $0.04(0.02)$ & & $-0.02(0.04)$ \\
\hline A-secure & $-0.05(0.02)^{* *}$ & $-0.05(0.01)^{* *}$ & $0.01(0.03)$ & $0.01(0.03)$ \\
\hline By Group & & $0.11(0.03)^{* *}$ & & $0.05(0.06)$ \\
\hline By Culture & & $-0.03(0.03)$ & & $0.01(0.05)$ \\
\hline P-family & $-0.02(0.01)$ & $-0.02(0.01)$ & $-0.05(0.02)^{*}$ & $-0.05(0.02)^{*}$ \\
\hline By Group & & $-0.01(0.03)$ & & $-0.05(0.06)$ \\
\hline By Culture & & $-0.02(0.03)$ & & $0.08(0.06)$ \\
\hline P-self & $0.00(0.01)$ & $-0.00(0.01)$ & $-0.10(0.02)^{* *}$ & $-0.10(0.02)^{* *}$ \\
\hline By Group & & $0.05(0.02)^{*}$ & & $0.02(0.05)$ \\
\hline By Culture & & $0.04(0.02)$ & & $-0.03(0.04)$ \\
\hline P-roles & $-0.01(0.01)$ & $-0.01(0.01)$ & $-0.04(0.02)^{*}$ & $-0.05(0.02)^{*}$ \\
\hline By Group & & $0.01(0.02)$ & & $0.04(0.04)$ \\
\hline By Culture & & $0.03(0.02)$ & & $0.01(0.04)$ \\
\hline P-secure & $-0.04(0.01)^{* *}$ & $-0.04(0.01)^{* *}$ & $-0.06(0.03)^{*}$ & $-0.06(0.03)^{*}$ \\
\hline By Group & & $0.06(0.03)^{*}$ & & $0.03(0.06)$ \\
\hline By Culture & & $-0.03(0.03)$ & & $0.06(0.06)$ \\
\hline
\end{tabular}

$* p<0.05 . * * p<0.01$.

\section{Daily Stresses, Psychological Well-Being, and Marital Satisfaction}

As expected, the findings support the notion that stress has a deleterious effect on people's psychological well-being and marital relationships, as all stress domains were negatively associated with these aspects of participants' lives. Also not surprising were the findings that family-related stresses were primarily correlated with marital satisfaction and that selfelated stresses were mainly correlated with psychological wellbeing. These findings hold true for both Jews and Arabs with either idiocentric or allocentric orientations. These observations reflect the idiocentric nature of focusing on the self and individual well-being and the allocentric nature of focusing on the group and sense of belonging. At the same time, differences were found between Jews and Arabs (e.g., in the effects of fam- ily, self, and role-related stress on psychological well-being and marital satisfaction) and between participants with different cultural orientations within each socio-ethnic group.

The most intriguing finding, contrary to our expectation, relates to the association of security-related stress to psychological well-being and marital satisfaction. Despite the fact that security-related stress was reported to be the major source of stress, it was the least related to psychological well-being and marital satisfaction for all groups. Several explanations can account for this finding. First, it may be that this finding reflects a relatively limited variance in the appraisal of security-related stress, a phenomenon shared by many Israelis. Second, given the existential threat imposed by security-related events, it might be that people buffer such threats from affecting their daily routine by protecting their psychological wellbeing and marital relationships. Alternatively, it may be as- 
sumed that people do not allow such threats to affect their wellbeing and relationships in order to maintain functional daily routines. Finally, the findings suggest that given the ongoing nature of the socio-political situation and threats, it is the ordinary daily hassles (i.e., family strains, role responsibilities) that are responsible for daily fluctuations in personal well-being and marital relationships.

\section{How do Ethnic Affiliation and Cultural Orientation Shape Daily Experiences?}

Assuming that ethnicity and culture constitute the context of people's lives, we expected that both ethnic affiliation and cultural orientation would shape the extent to which psychological and marital well-being are related to the experience of daily hassles. The finding that only group affiliation appeared to shape such relations warrants further consideration. In general, differences between Jewish and Arab participants were found in the appraisal of daily stresses and their effect on psychological well-being and marital relationships, but few or no differences were attributed to their divergent cultural orientations. This finding may attest to the significance of context, as Arab families - whether idiocentric or allocentric - tend to reside within homogeneous communities and villages. Thus, for example, educated, economically advantaged, and liberal-minded Arab men and women may perceive their daily experiences in a more similar way to members of their community than to their Jewish counterparts with a similar cultural orientation. In addition, we argue that the findings reflect a more global socio-political context of life in Israel, which overrides differences in cultural orientation insofar as it reflects a more prominent aspect of personal identity.

\section{Conclusion}

Three main findings capture the essence of the current paper. First, security-related stress is perceived as the main source of stress for members of both ethnically-affiliated groups and with different cultural orientations; it appears to color all aspects of daily experiences. Second, security-related stress has little or no effect on sense of personal well-being and marital relationships on a daily basis. Third, socio-political affiliation overrides individual differences due to cultural orientation. The findings show that ethnic affiliation partly shapes the associations between daily hassles and personal and marital well-being, but that cultural orientation does not. In particular, belonging to the Jewish majority or to the Arab minority mirrors the socio-political context of this region, as it touches upon self and national identities. Within this context, socio-ethnic affiliation takes prominence over individual cultural orientation.

The current article may pave the way to a road less travelled: the understanding and delineation of factors that shape the effects of daily negative experiences among people of different ethnic and cultural identity living in the context of political hostilities. The case of Jewish and Arab citizens in Israel may be conceived as a natural laboratory from which initial generalizations can be made that may be applicable to similar situations. Needless to say, ethnic, cultural and religious conflicts exist in other countries around the globe, in which security or ethnic tensions may prevail. Further research may be carried out in other socio-political contexts to validate and refine our findings.

\section{Notes}

Researchers affiliated with an Israeli university and studying an Arab population may face some socio-political, cultural, and language-related issues. We made an effort to minimize these concerns by including an Arab research coordinator who helped develop, translate, and pre-test the questionnaires, and by having all interviews with Arab couples conducted by trained Arab interviewers. We also debriefed interviewers, both Jewish and Arab, to check whether respondents raised language or cultural issues.

\section{References}

Abdela, L. (2003). Kosovo: Missed opportunities, lessons for the future. Development in Practice, 13, 208-216. doi:10.1080/09614520302942

Babbie, E. (1989). The practice of social research (5th edition). Belmont, CA: Wadsworth.

Cassidy, T. (2000). Stress, healthiness and health behaviours: An exploration of the role of life events, daily hassles, cognitive appraisal and the coping process. Counseling Psychology Quarterly, 13, 293311. doi:10.1080/09515070010028679

Central Bureau of Statistics, (2008). Statistical abstracts of Israel. Jerusalem, Israel: Author.

Cooper, C., \& Denner, J. (1998). Theories linking culture and psychology: Universal and community-specific processes. Annual Review of Psychology, 49, 559-584. doi:10.1146/annurev.psych.49.1.559

DeLongis, A., Coyne, J. C., Dakof, G., Folkman, S., \& Lazarus, R. S. (1982). The relationship of hassles, uplifts, and major life events to health status. Health Psychology, 1, 119-136. doi:10.1037/0278-6133.1.2.119

DeLongis, A., Folkman, S., \& Lazarus, R. S. (1988). The impact of daily stress on health and mood: Psychological and social resources as mediators. Journal of Personality and Social Psychology, 54, 486-495. doi:10.1037/0022-3514.54.3.486

Florian, V., Mikulincer, M., \& Weller, A. (1993). Does culture affect perceived family dynamics? A comparison of Arab and Jewish adolescents in Israel. Journal of Comparative Family Studies, 24, 189-201.

Hahn, S. E., \& Smith, C. S. (1999). Daily hassles and chronic stressors: Conceptual and measurement issues. Stress Medicine, 15, 89-101. doi:10.1002/(SICI)1099-1700(199904)15:2<89::AID-SMI789>3.0.C $\underline{\mathrm{O} ; 2-\mathrm{O}}$

Haj-Yahia, M. (1997). Culturally sensitive supervision of Arab social work students in Western Universities. Social Work, 42, 166-174.

Hofstede, G. (1980). Culture's consequences: International differences in work-related values. Beverly Hills, CA: Sage.

Hughes, D., Seidman, E., \& Williams, N. (1993). Cultural phenomena and the research enterprise: Toward a culturally anchored methodology. American Journal of Community Psychology, 21, 687-703. doi:10.1007/BF00942243

Johnson, J. G. \& Sherman, M. F. (1997). Daily hassles mediate the relationship between major life events and psychiatric symptomatology: Longitudinal findings from an adolescent sample. Journal of Social and Clinical Psychology, 16, 389-404. doi:10.1521/jscp.1997.16.4.389

Karney, B., Story, L. B., \& Bradbury, T. N. (2005). Marriages in context: Interaction between chronic and acute stress among newlyweds. In T. A. Revenson, K. Kayser, \& G. Bodenmann (Eds.), Couples coping with stress: Emerging perspectives on dyadic coping. Washington, DC: American Psychological Association.

Kashima, E. S., \& Hardie, E. A. (2000). The development and validation of the Relational, Individual, and Collective self aspects (RCI) scale. Asian Journal of Social Psychology, 3, 19-48.

Kitayama, S., Duffy, S., \& Uchida, Y. (2007). Self as cultural mode of 
being. In S. Kitayama \& D. Cohen (Eds.), Handbook of cultural psychology (pp. 136-174). New York: Guilford.

Kitayama, S., Markus, H. R., \& Lieberman, C. (1995). The collective construction of self esteem: Implications for culture, self, and emotion. In J. A. Russell, J. M. Fernandez-Dols, A. S. Manstead, \& J. C. Wellenkamp (Eds.), Everyday conception of emotion (pp. 523-552). Boston, MA: Kluwer Academic Publishers.

Laungani, P. (1995). Stress in Eastern and Western cultures. Stress and Emotion: Anxiety, Anger, and Curiosity, 15, 265-280.

Laungani, P. (2001). The influence of culture on stress: India and England. In L. L. Adler \& U. P. Gielen (Eds.), Cross cultural topics in psychology (pp. 149-169). Westport, CT: Praeger.

Lavee, Y., \& Ben-Ari, A. (2003). Daily stresses and uplifts during times of political tension: Jews and Arabs in Israel. American Journal of Orthopsychiatry, 7, 65-73. doi:10.1037/0002-9432.73.1.65

Lavee, Y., \& Ben-Ari, A. (2008). The association of daily hassles and uplifts with family and life satisfaction: Does cultural orientation make a difference? American Journal of Community Psychology, 41, 89-98. doi:10.1007/s10464-007-9146-8

Lavee, Y., \& Katz, R. (2003). The family in Israel: Between tradition and modernity. Marriage and Family Review, 35, 193-217. doi:10.1300/J002v35n01_11

Markus, H. R., \& Kitayama, S. (2003). Models of agency: Sociocultural diversity in the construction of action. In V. Murphy-Berman \& J. Berman (Eds.), Cross-cultural differences in perspectives on the self (pp. 18-74). Lincoln, NE: University of Nebraska Press.

Matsumoto, D., Takeuchi, S., Andayani, S., Kouznetsova, N., \& Krupp, D. (1998). The contribution of individualism vs. collectivism to cross-national differences in display rules. Asian Journal of Social Psychology, 1, 147-165. doi:10.1111/1467-839X.00010

Mesquita, B., \& Frijda, N. H. (1992). Cultural variations in emotions: A review. Psychological Bulletin, 112, 179-204.

doi:10.1037/0033-2909.112.2.179

Milgram, N. (1993). War-related trauma and victimization: Principles of traumatic stress prevention in Israel. In J. P. Wilson \& B. Raphael (Eds.), International handbook of traumatic stress syndromes (pp. 811-820). New York: Plenum.

O’Donnell, C. R. (2006). Beyond diversity: Toward a cultural community psychology. American Journal of Community Psychology, 37, 1-7. doi:10.1007/s10464-005-9010-7

Oyserman, D., \& Lee, S. W. S. (2008). Does culture influence what and how we think? Effects of priming individualism and collectivism. Psychological Bulletin, 134, 311-342. doi:10.1037/0033-2909.134.2.311

Scherer, K. R. (1997). The role of culture in emotion-antecedent appraisal. Journal of Personality and Social Psychology, 73, 902-922. doi:10.1037/0022-3514.73.5.902c

Slavin, L. A., Rainer, K. L., McCreary, M. L., \& Gowda, K. K. (1991). Toward a multicultural model of the stress process. Journal of Counseling and Development, 70, 156-163

Smith, P. B., \& Bond, M. H. (1993). Social Psychology across cultures: Analysis and perspectives. Hemel Hempstead, England: Harvester Wheatsheaf.

Triandis, H. C. (1995). Individualism and collectivism. Boulder, CO: Westview.

Triandis, H. C. (2001). Individualism-collectivism and personality. Journal of Personality, 69, 907-924. doi:10.1111/1467-6494.696169

Triandis, H. C., Leung, K., Villareal, M., \& Clack, F. L. (1985). Allocentric vs. idiocentric tendencies: Convergent and discriminant validation. Journal of Research in Personality, 19, 395-415. doi:10.1016/0092-6566(85)90008-X

Uchida, Y., Kitayama, S., Mesquita, B., Reyes, J. A. S., \& Morling, B (2008). Is perceived emotional support beneficial? Well-being and health in independent and interdependent cultures. Personality and Social Psychology Bulletin, 34, 741-754. doi:10.1177/0146167208315157

Van Eck, M., Nicolson, N. A., \& Berkhof, J. (1998). Effects of stressful daily events on mood states: Relationship to global perceived stress. Journal of Personality and Social Psychology, 75, 1572-1585. doi:10.1037/0022-3514.75.6.1572

Watson, D., Clark, L. A., \& Tellegen, A. (1988). Development and validation of brief measures of positive and negative affect: The PANAS scales. Journal of Personality and Social Psychology, 54, 1063-1070. doi:10.1037/0022-3514.54.6.1063

Williams, R., Zyzanski, S., \& Wright, A. L. (1992). Life events and daily hassles and uplifts as predictors of hospitalization and outpatient visitation. Social Science and Medicine, 34, 763-768. doi:10.1016/0277-9536(92)90363-U

Wolf, T. M., Elston, R. C., \& Kissling, G. E. (1989). Relationship of hassles, uplifts, and life events to psychological well being of freshmen medical students. Behavioral Medicine, 15, 37-45. doi:10.1080/08964289.1989.9935150 